\title{
Assessing the impacts of changes in the Hadley Circulation on stationary Rossby wave propagation
}

\author{
$\underline{\text { A.C.V. Freitas }}^{\text {a }}$, T. J. O'Kane ${ }^{\text {b }}$, J. S. Frederiksen ${ }^{\text {c }}$ and T. Ambrizzi ${ }^{\text {a }}$ \\ ${ }^{a}$ Institute of Astronomy, Geophysics and Atmospheric Sciences, São Paulo-Brazil; ${ }^{b}$ CSIRO Marine and \\ Atmospheric Research, Hobart-Australia; ${ }^{c}$ CSIRO Marine and Atmospheric Research, Aspendale-Australia \\ Email: ana.freitas@,csiro.au
}

\begin{abstract}
The Hadley Cell (HC) plays a key role in the climate system. Generally defined as the zonal mean meridional mass circulation in the atmosphere bounded roughly by $30^{\circ} \mathrm{S}$ and $30^{\circ} \mathrm{N}$, with warmer air rising in the tropics and colder air sinking in the subtropics, this circulation transports momentum flux to the subtropics and heat from the tropics to the subtropics and to high latitudes through extra-tropical baroclinic eddies broadly organized into storm tracks and stationary Rossby waves. Through anomalous upper tropospheric divergence, modifications in the $\mathrm{HC}$ are connected to changes in the generation of Rossby waves that propagate into the extra-tropics. Thus, tropical variability affects the extra-tropical atmospheric circulation.
\end{abstract}

Changes in the location, intensity or seasonality of major climatological features of the general circulation, such as the HC or Rossby waves, can have important implications for regional climates by modifying patterns of temperature and precipitation. Several studies have identified that, in the late 1970s and early 1980 s, a major shift occurred in the structure of large-scale circulation in both hemispheres, including a weakening of HC. Thus, in this paper we investigate how the changes in the HC, which occurred in the mid1970s, have affected the stationary Rossby wave energy propagation in the Southern Hemisphere (SH) extratropics. We have employed the CSIRO Mk-3L general circulation model in a simulation with observed sea surface temperatures (SSTs) and time evolving historical carbon dioxide concentrations. Our focus is on the performance of the model in simulating the climatology for the twenty year periods 1949-68 and 1975-94 and on comparisons with the corresponding observations.

We find that the model is quite skilful in reproducing the broad features of the important inter-decadal changes that occurred in the mid-1970s.

We have also analysed the Rossby Wave Source (RWS) and mid-latitude circulation responses at upper levels associated with tropical variability. The RWS forcing is found to be located directly over the high latitude downward branch of the local HC, which is associated with upper-level convergence zones. The vortex stretching term is the largest contribution to the total RWS and the term of absolute vorticity advection by the divergent flow is mainly associated with the anticyclonic anomaly sources in the subtropics.

The results also show that the weakening of the HC, which occurred in the period 1975-1994, leads to higher pressure developing over southern Australia, especially over southwestern Australia, contributing to rainfall reductions in these regions.

Keywords: Hadley circulation, climate modelling, stationary Rossby waves 
Freitas et al., Assessing the impacts of changes in the Hadley Circulation on stationary Rossby wave propagation.

\section{INTRODUCTION}

The Hadley Cell (HC), generally defined as the zonal mean meridional mass circulation in the atmosphere, is bounded roughly by $30^{\circ} \mathrm{S}$ and $30^{\circ} \mathrm{N}$, with warmer air rising in the tropics and colder air sinking in the subtropics. The deep convection in the rising branch of the HC and the associated anomalous divergence at high levels causes a disturbance in the vorticity field and triggers large-scale atmospheric Rossby waves that can propagate into higher latitudes along a ray path (Hoskins and Karoly, 1981). These stationary Rossby waves are usually called teleconnection patterns.

Freitas and Ambrizzi (2012), in a observational study for the 1979-2010 austral winter period, found that for weak HC years, a wave train emanated from the subtropical central-west Indian Ocean in an arc-like route, with zonal wavenumber three in the polar jet waveguide, and reached the north of South America. For strong $\mathrm{HC}$ years, the authors found a wave train with zonal wavenumber four trapped inside the polar jet waveguide, emanating from subtropical central-east Indian Ocean and reaching the subtropical west coast of Africa. They showed that over South America a HC weakening can lead to a very cold and rainy winter in the southwest of the continent and a mild warm and dry winter in the Brazilian states of Minas Gerais and Bahia. An almost opposite pattern was observed when the HC strengthens.

Thus, tropical variability affects the extra-tropical atmospheric circulation with important implications for regional climates by modifying patterns of temperature and precipitation. Hence, it is important to investigate how the changes in the tropical circulation, in particular the HC, impact upon the extra-tropical planetary waves and their propagation.

Several studies have shown that, in the late 1970s and early 1980s, a major shift occurred in the structure of large-scale circulation in both hemispheres (e.g., Freitas and Rao, 2011; Frederiksen and Frederiksen, 2005; 2007 - hereafter FF05, FF07, respectively). In the Southern Hemisphere (SH), FF05 and FF07 found that there were quite large changes in thermal structure and atmospheric circulation, between the periods of 19491968 and 1975-1994. Regarding the changes in thermal structure, they found a significant warming of the SH troposphere, south of $30^{\circ} \mathrm{S}$ in the period 1975-1994, resulting in a reduction of the equator-to-pole temperature gradient. This in turn resulted in a $17 \%$ reduction in the strength of the peak zonal wind over southern Australia and a reduction in the growth rates of storms.

General Circulation Models (GCMs) are an important tool to study the climate change issue and provide the basis for climate change projections. A correct simulation of the present-day atmospheric general circulation is crucial for build climate change projections more consistent and reliable.

Therefore, the aims of this paper are: to establish the degree of skill of an atmospheric simulation with observed sea surface temperatures (SSTs) from the CSIRO Mk-3L model in reproducing some of the important inter-decadal changes found by FF05 and FF07; and to investigate how the shifts in the HC, which occurred in the mid-1970s, affect the stationary Rossby wave energy propagation in the SH extra-tropics.

\section{DATA AND METHODS}

\subsection{Model details}

This study employs the CSIRO Mk3L model version 1.2, a general circulation model designed for the study of climate variability and change on millennial timescales (Phipps, 2010). The atmospheric component of $\mathrm{Mk} 3 \mathrm{~L}$ is based on the CSIRO Mk3 model (Gordon et al., 2002) with rhomboidal 21 resolution, forced by the observed SSTs and historical time evolving carbon dioxide concentrations. A hybrid vertical coordinate is used, with 18 vertical levels. The model incorporates both a cumulus convection scheme and a prognostic stratiform cloud scheme.

The atmospheric component contains descriptions of atmospheric transport, radiative exchange, convection and clouds. The radiation calculations treat longwave and shortwave radiation separately, and include the effects of carbon dioxide, ozone, water vapour and clouds. A model of land surface interaction and of sea ice is included.

\subsection{SST Data}

The surface boundary condition of SST is obtained from the monthly mean of Hadley Centre Global Sea Ice and Sea Surface Temperature (HADISST) data set on a $1^{\circ} \times 1^{\circ}$ grid from 1870 to present (Rayner et al., 2003). Data set is available on the internet: http://www.metoffice.gov.uk/hadobs/hadisst/data/download.html. 
Freitas et al., Assessing the impacts of changes in the Hadley Circulation on stationary Rossby wave propagation.

\subsection{Methods}

This study is based on an analysis of the atmospheric simulation by the CSIRO Mk3L model with observed SSTs and historical time evolving carbon dioxide concentrations (hereafter denominated ATM simulation). The stand-alone atmospheric model was chosen since the major features of the tropical atmospheric circulation are determined by the SST and, in the coupled GCMs, the SST response may differ from the observed SST evolution, thereby affecting the fidelity of the simulated circulation results.

The global SH mean July climate fields for the periods 1949-1968 and 1975-1994 are analyzed. We focus on the $200 \mathrm{hPa}$ level since the divergence has its maximum amplitude at this level.

\subsubsection{Definition of the HC}

The $\mathrm{HC}$ is described in terms of the mean meridional mass streamfunction $\psi$ (Oort and Yienger, 1996) computed using the zonal-mean meridional wind and the surface pressure according to the following equation:

$$
\psi=\frac{2 \pi a \cos \phi}{g} \int_{p}^{p s}[\bar{v}(p, \phi)] d p
$$

where $a$ is the earth's radius, $\phi$ is the latitude, $\bar{v}$ is the zonally averaged temporal mean of meridional velocity, $p$ is the pressure, $p s$ is the surface pressure, $g$ is the acceleration of gravity. This formula quantifies air mass transport in the tropics and subtropics and the strength of the HC is defined by the maximum value of the zonal mean meridional mass streamfunction.

\subsubsection{Rossby wave source}

The changes in tropical forcing can be approximated by changes in the Rossby wave source ( $R W S$ ), defined by Sardeshmukh and Hoskins (1988) as:

$$
R W S=-\zeta D-\overrightarrow{V_{\chi}} \cdot \nabla \zeta=-\nabla \cdot\left(\overrightarrow{V_{\chi}} \zeta\right)
$$

where $\zeta=\xi+f$ is the absolute vorticity, $\xi$ is the relative vorticity, $f$ is the Coriolis parameter, $\overrightarrow{V_{\chi}}$ is the divergent component of the wind velocity field and $D$ is the horizontal divergence $\partial u / \partial x+\partial v / \partial y$. The first term $(-\zeta D)$ is the vortex stretching term (hereafter VS), or the generation of vorticity by divergence, and the second term $\left(-\overrightarrow{V_{\chi}} \cdot \nabla \zeta\right)$ is the advection of absolute vorticity by divergent flow (hereafter AV).

A similar analysis method to that of Tyrrell and Karoly (1996) has been applied to study the RWS and upper level mid-latitude circulation responses associated with the tropical convection. We have focused on the difference between the two periods (1975-94 and 1949-68), since it portray the changes that occurred in the mid-1970s.

\section{RESULTS}

Some of the results found by FF05 and FF07 are compared with the ATM simulation to establish if the model is reproducing the important inter-decadal changes discussed by the authors. Figure 1 shows the vertical cross-section of July zonal wind found by FF05 (left column) and for the ATM simulation (right column). At about $200 \mathrm{hPa}$, the maximum in the zonal wind strength near $30^{\circ} \mathrm{S}$ for the $1949-1968$ basic state [Figure 1 (a)] is reproduced by the simulation with slight overestimated values [Figure 1 (c)]. FF05 and FF07 noted, for the latter period (1975-1994) in the upper troposphere, a reduction in the zonal wind near $30^{\circ} \mathrm{S}$ and, an increase near $45^{\circ} \mathrm{S}$ and in the main northern hemisphere jet core near $35^{\circ} \mathrm{N}$ [Figure 1 (b)]. The ATM simulation is quite skilful in reproducing these changes, although, it underestimates the magnitude [Figure $1(d)]$.

FF05 and FF07 found some other important inter-decadal changes after the mid-1970s, which include a significant warming south of $30^{\circ} \mathrm{S}$, leading to a reduction in the equator-to-pole temperature gradient, a modification in the strength of the Antarctic Oscillation, and a reduced winter rainfall particularly in the southwest of western Australia. These changes are also reproduced by the ATM simulation (not shown). 
Freitas et al., Assessing the impacts of changes in the Hadley Circulation on stationary Rossby wave propagation.

Thus, the ATM simulation can capture some of the important inter-decadal changes found by FF05 and FF07.

FF05 and FF07 also noticed modifications in the HC, which is certainly expected, since these changes are directly associated with the alterations in the zonal wind and in the equator-to-pole temperature gradient cited above. Figure 2 shows, for the ATM simulation, the zonal mean meridional mass streamfunction for the period 1949-1968 and for the difference between the two periods. A weakening of the HC can be noted in the latter period (1975-1994). This weakening can also be confirmed through the zonal mean divergence at 200 $\mathrm{hPa}$ (not shown). In the latter period the peak of divergence is smaller. A weaker (stronger) HC leads to a smaller (larger) lifting mass and so, less (more) divergence in the upper troposphere. The zonal mean meridional wind is also reduced in the latter period (not shown).

Although, the upper tropospheric zonal mean divergence reduces in the latter period, some local increases can exist in the divergence field [see Figure 4 (b)]. In this regard, it is worth to noting that besides the tropical convection, other process, such as baroclinic waves or radiative cooling, could be also responsible for the divergence patterns, particularly in the subtropics and middle latitudes (Tyrrell and Karoly, 1996).

(a)

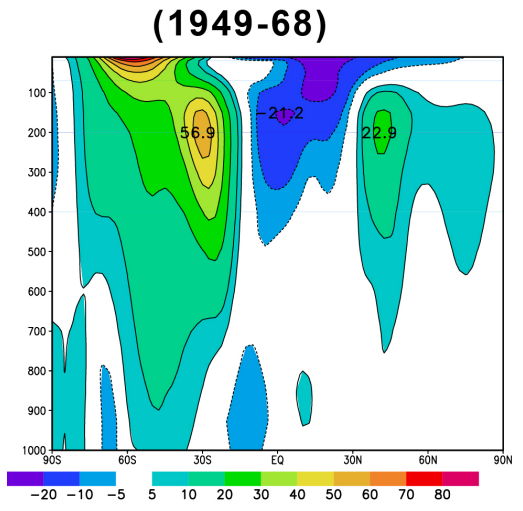

(b)

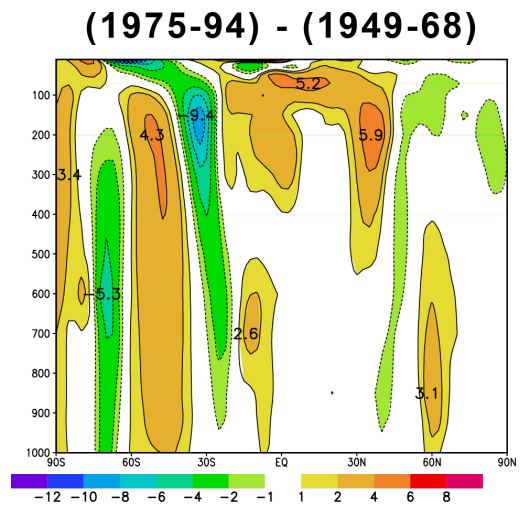

(c)

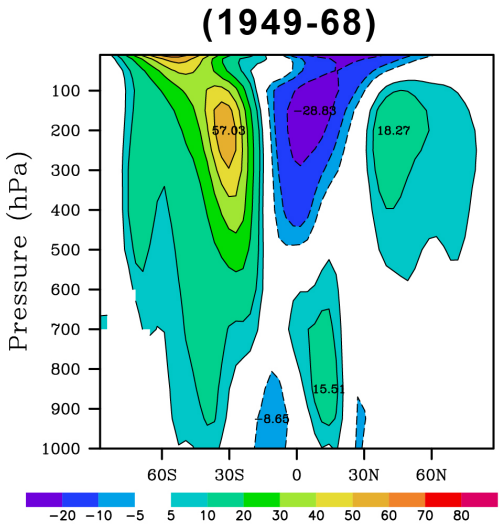

(d)

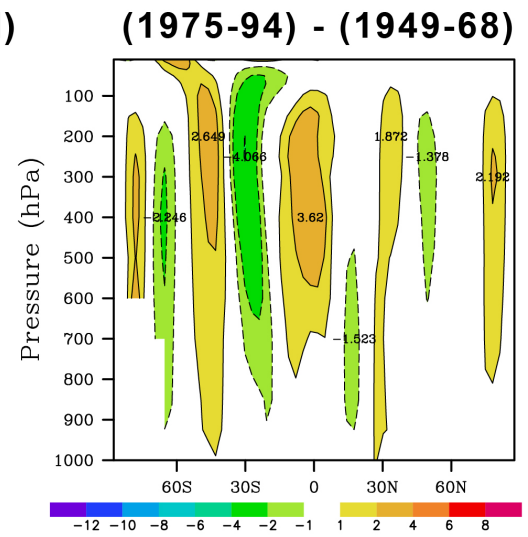

Figure 1. Vertical cross-section of July zonal wind $\left(\mathrm{m} \mathrm{s}^{-1}\right)$ averaged between $100^{\circ}$ and $130^{\circ} \mathrm{E}$ as a function of latitude and pressure (hPa) for the 1949-1968 basic state, and for the difference (1975-1994) - (1949-1968). Plots (a) and (b) obtained from FF05 and (c) and (d) for the ATM simulation. Contour intervals are 10 and $2 \mathrm{~m} \mathrm{~s}^{-1}$, respectively.

(a)

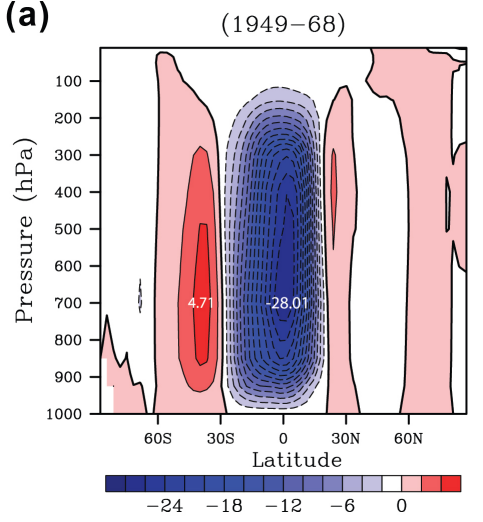

(b)

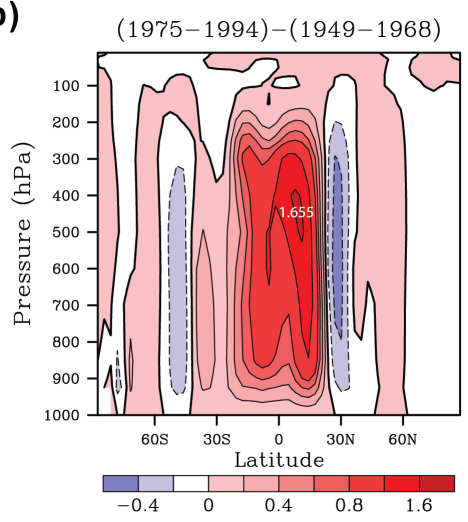

Figure 2. Zonal mean meridional mass streamfunction $\left({\mathrm{x} 10^{10}}^{\mathrm{kg} \mathrm{s}} \mathrm{s}^{-1}\right)$ based on the ATM simulation for the 1949-1968 basic state (a) and for the difference (1975-1994)-(1949-1968) (b). Contour intervals are $2 \mathrm{x}$ $10^{10} \mathrm{~kg} \mathrm{~s}^{-1}$ and $0.2 \times 10^{10} \mathrm{~kg} \mathrm{~s}^{-1}$, respectively. 
Freitas et al., Assessing the impacts of changes in the Hadley Circulation on stationary Rossby wave propagation.

(a)

(b)

Figure 3. Rossby wave source $\left(\times 10^{-11} \mathrm{~s}^{-2}\right)$ at $200 \mathrm{hPa}$ based on the ATM simulation for the 1949-1968 basic state (a) and for the difference (19751994)- (1949-1968) (b). Contour intervals are $5 \times 10^{-11} \mathrm{~s}^{-2}$ and $3 \times 10^{-11} \mathrm{~s}^{-2}$, respectively. The symbols AS and CS represent anticyclonic and cyclonic anomaly sources, respectively.

term contributes most to the sources in the subtropical regions (not shown).
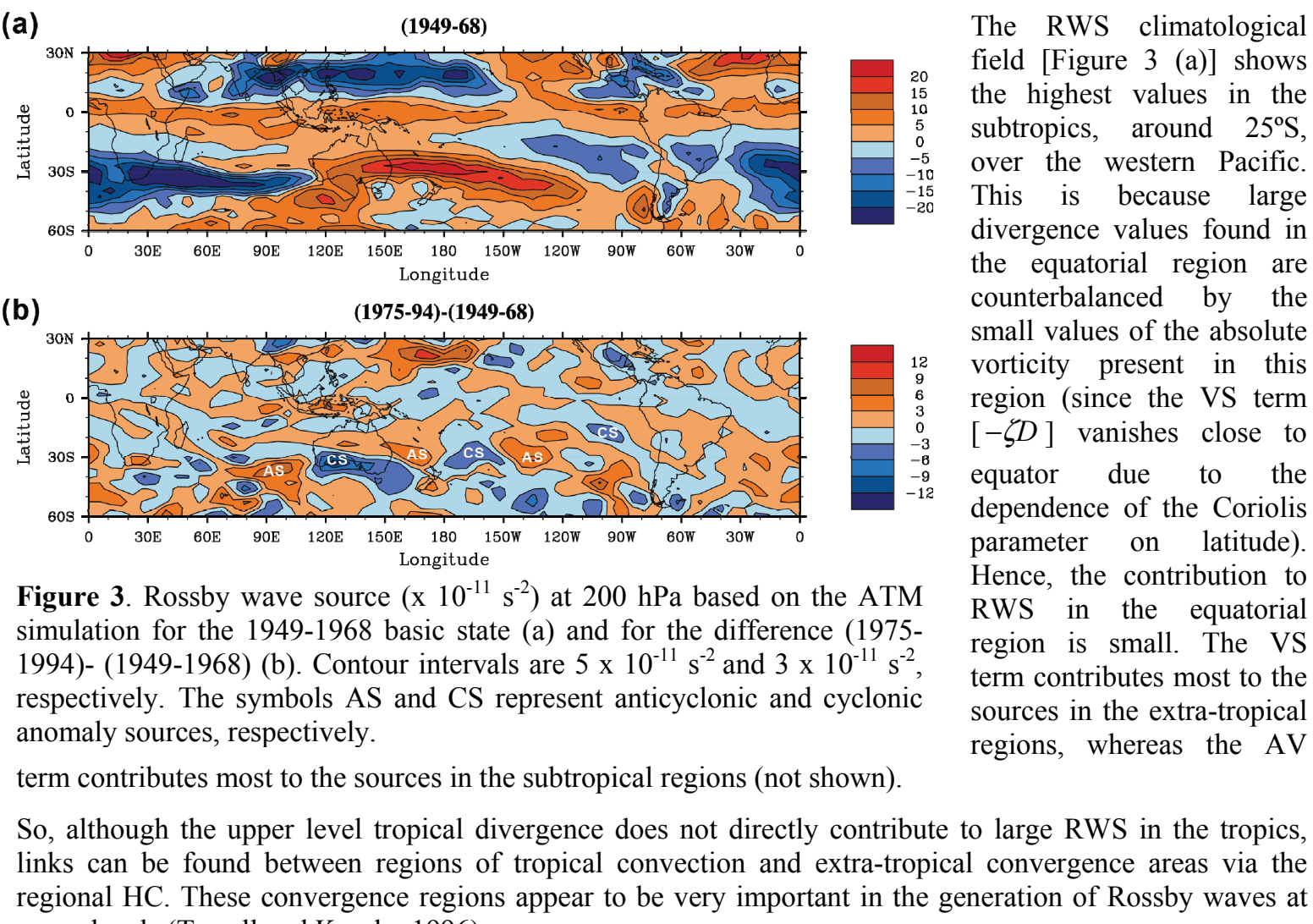

The RWS climatological field [Figure 3 (a)] shows the highest values in the subtropics, around $25^{\circ} \mathrm{S}$, over the western Pacific. This is because large divergence values found in the equatorial region are counterbalanced by the small values of the absolute vorticity present in this region (since the VS term [ $\zeta D]$ vanishes close to equator due to the dependence of the Coriolis parameter on latitude). Hence, the contribution to RWS in the equatorial region is small. The VS term contributes most to the sources in the extra-tropical regions, whereas the $\mathrm{AV}$

So, although the upper level tropical divergence does not directly contribute to large RWS in the tropics, links can be found between regions of tropical convection and extra-tropical convergence areas via the regional HC. These convergence regions appear to be very important in the generation of Rossby waves at upper levels (Tyrrell and Karoly, 1996).

(a)

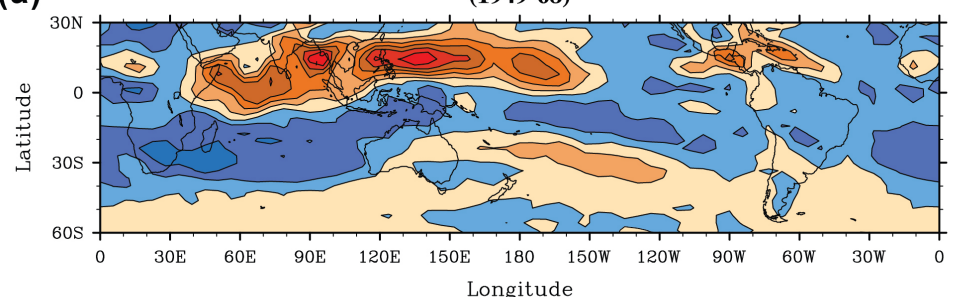

(b)



Figure 4. Divergence $\left(\times 10^{-6} \mathrm{~s}^{-1}\right)$ based on the ATM simulation at $200 \mathrm{hPa}$ for the 1949-1968 basic state (a) and for the difference (1975-1994)-(19491968) together with the divergent wind vectors. Contour intervals are $1.5 \mathrm{x}$ $10^{-6} \mathrm{~s}^{-1}$ and $0.5 \times 10^{-6} \mathrm{~s}^{-1}$, respectively. The symbol C represents convergence anomaly zones.

that negative values in the RWS field are focused over the subtropical east Pacific, Atlantic and Indian Oceans. Some important cyclonic (anticyclonic) anomaly sources are marked with the letters CS (AS) in Figure 3 (b). Many of the CS-AS sources lies in the band of positive RWS over the western Pacific [Figure 3 (a)].

Cyclonic anomaly sources (Figure 3 (b) - letters CS) are present in the convergence anomaly zones (Figure 4 (b) - letters C). These cyclonic anomaly sources are predominantly associated with the VS term. However, we also found that there is a small positive contribution of the AV term to the southern Australia source and a

Upper-level convergence zones associated with the downward branch of the local $\mathrm{HC}$ tend to be localized rather than spread out uniformly over the globe (Tyrrell and Karoly, 1996). To clarify, three of the convergence anomaly zones, found with the aid of divergent wind field, are marked with the letter $\mathrm{C}$ in the Figure 4 (b). Here, the word "anomaly" represents the difference between the two periods analysed.

Cyclonic vorticity is negative in the SH. Therefore, a negative value in the RWS field refers to cyclonic source of Rossby waves. The climatological field [Figure 3 (a)] shows Pacific, Atlantic and Indian . 
Freitas et al., Assessing the impacts of changes in the Hadley Circulation on stationary Rossby wave propagation.

small negative contribution to the other sources (not shown). Figure 3 (b) also indicates three important regions of anticyclonic anomaly sources (letters AS), located around $30^{\circ} \mathrm{S}$, influenced by the VS (mainly) and AV terms. The first is over the eastern Indian Ocean, the second is over the east coast of Australia (with important contribution of the AV term) and, the third is in the central Pacific.

The stationary wave streamfunction field is obtained when the zonal average is removed from the full field of the streamfunction. In the $\mathrm{SH}$, negative (positive) values of this field are associated with ridges (troughs). Figure 5 shows this field at $200 \mathrm{hPa}$ for the period 1949-1978 and for difference between the two periods.

(a)

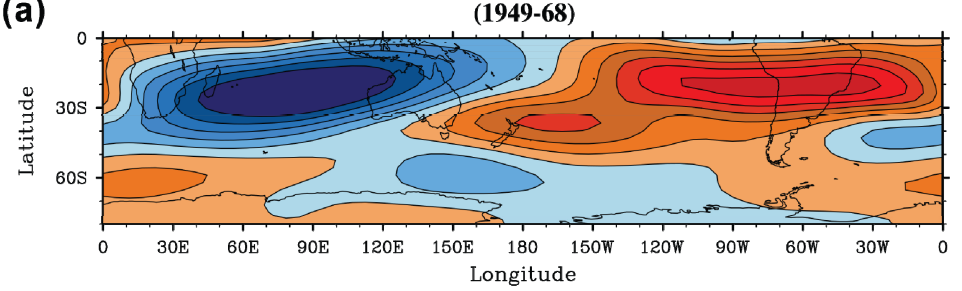

(b)

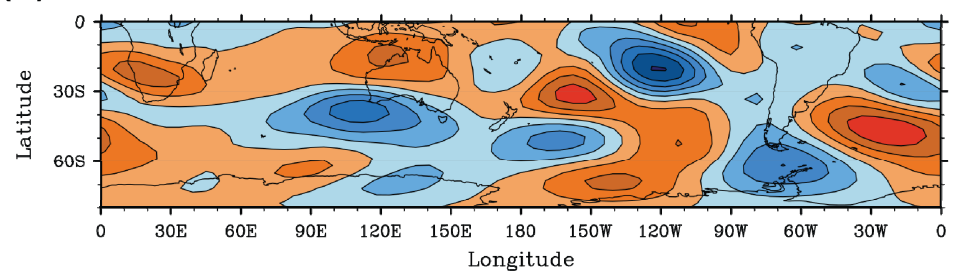

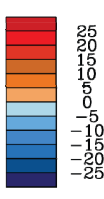

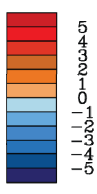

Figure 4 (b) shows that immediately downstream of the convergence (divergence) anomaly zones around $30^{\circ} \mathrm{S}$, there are troughs (ridges) [Figure 5 (b)], as a response to the cyclonic (anticyclonic) anomaly sources [Figure 3 (b)].

The RWS and the Rossby wave propagation are strongly influenced by the basic state. However, Freitas and Ambrizzi (2012) also found, using a different basic state (19792010), that when the HC weakens there is a ridge over the southwestern simulation at $200 \mathrm{hPa}$ for the 1949-1968 basic state (a) and for the difference (1975-1994)-(1949-1968) (b). Contour intervals are $5 \mathrm{~km}^{2} \mathrm{~s}^{-1}$ and $1 \mathrm{~km}^{2} \mathrm{~s}^{-1}$, respectively.

an Ocean) and low pressure Australia (as an outcome of an anticyclonic anomaly source over the eastern Indian Ocean) an
over the east coast of Australia (as a result of a cyclonic anomaly source over south Australia).

The ridge over southern Australia, especially over southwestern Australia, can also be seen in the fields of mean sea level pressure and stationary wave geopotential at $200 \mathrm{hPa}$ (not shown). The precipitation field is also consistent with these results, showing decrease in southern Australia and increase towards the north of the continent (not shown).

In our simulations, and in the observations (FF05, FF07), changes between 1949-68 and 1975-94 in the SSTs and radiative forcing cause a reduction in the atmospheric temperature gradient around $30^{\circ} \mathrm{S}$ and, by thermal wind balance, a reduction in the vertical shear of the zonal wind. As well there are changes in the static stability (FF05, FF07) and the HC as seen in the mean meridional mass streamfunction (Figure 2), the latitude of the high pressure belt (not shown) and in the eddy fluxes of heat and momentum (Zidikheri and Frederiksen, 2013). FF05 and FF07 argued that a primary cause of the rainfall reduction over the southwest of western Australia in the latter period is the reduction in the intensity of cyclogenesis due to a decrease in the peak jet stream and particularly in the associated reduction in the vertical wind shear and baroclinicity. Here we have shown that the weakening of the $\mathrm{HC}$ seems to play an important role in developing higher pressure over southern Australia, especially over southwest Western Australia, and may lead to rainfall reductions in this region. These results are consistent with those of Frederiksen and Frederiksen (1992), who found that the primary determinant of storm track mode growth and location is the strength and location of the baroclinic geostrophic wind with ageostrophic effects, such as associated with the HC, playing an important subsidiary role in storm track location. FF07 find that changes in the static stability between 194968 and 1975-94 in fact try to counteract the reduction in storm formation, particularly over the southwest of Western Australia.

\section{CONCLUSIONS}

In this paper we have investigated how the changes in the HC, which occurred in the mid-1970s, affected the stationary Rossby wave energy propagation in the SH extra-tropics using a simulation with observed SSTs and historical carbon dioxide concentrations from the CSIRO Mk3L model and, analysing the 1949-1968 basic state in comparison with the 1975-1994 basic state. 
Freitas et al., Assessing the impacts of changes in the Hadley Circulation on stationary Rossby wave propagation.

Using a similar analysis method to that of Tyrrell and Karoly (1996), we have examined the RWS and midlatitude circulation responses at upper levels associated with tropical variability. The RWS forcing is located directly over the high latitude downward branch of the local HC, which is associated with upper-level convergence zones. The VS term is the largest contribution to the total RWS and the most important influence of AV term is associated with anticyclonic anomaly sources in the subtropics.

Our results have shown that the CSIRO Mk3L model is quite skilful in reproducing the broad features of the important inter-decadal changes that occurred in the mid-1970s. The weakening of the HC, which occurred in the period 1975-1994, leads to higher pressure developing over southern Australia, especially over southwestern Australia, contributing to rainfall reductions in these regions.

\section{ACKNOWLEDGMENTS}

A.C.V. Freitas acknowledges FAPESP (Fundação de Amparo a Pesquisa do Estado de São Paulo) for financial support (2012/14231-1) and CSIRO Marine and Atmospheric Research for technical support. T.J. O'Kane is supported by an Australian Research Council Future Fellowship. We are grateful to Steven Phipps and Jennifer Whelan for the assistance with the CSIRO Mk3L model. This work is partly supported by the Australian Government Department of Climate Change and Energy Efficiency.

\section{REFERENCES}

Frederiksen, C.S. and Frederiksen, J.S. (1992). Northern Hemisphere storm tracks and teleconnection patterns in primitive equation and quasigeostrophic models, J. Atmos. Sci., 49(16), 1443-1458.

Frederiksen, J.S. and Frederiksen, C.S. (2005). Decadal changes in Southern Hemisphere winter cyclogenesis, CSIRO Marine and Atmospheric research paper; 002, Aspendale, Vic.: CSIRO Marine and Atmospheric Research. V, available at: http://www.cmar.csiro.au/e-print/open/frederiksenjs 2005b.pdf (last access: June 2013), 29 pp.

Frederiksen, J.S. and Frederiksen, C.S. (2007). Interdecadal changes in southern hemisphere winter storm track modes, Tellus A, 59, 599-617

Freitas, A.C.V. and Rao, V.B. (2011). Multidecadal and interannual changes of stationary Rossby waves. Q.J.R. Meteorol. Soc., 137, 2157-2173.

Freitas, A.C.V. and Ambrizzi, T. (2012). Changes in the austral winter Hadley circulation and the impact on stationary Rossby waves propagation, Advances in Meteorology, Article ID 980816, 15 pages, doi:10.1155/2012/980816.

Gordon, H.B., Rotstayn, L.D., McGregor, J.L., Dix, M.R., Kowalczyk, E.A., O’Farrell, S.P., Waterman, L.J., Hirst, A.C., Wilson, S.G., Collier, M.A., Watterson, I.G., and Elliott, T.I. (2002). The CSIRO Mk3 climate system model, Technical Paper 60, CSIRO Atmospheric Research.

Hoskins, B.J. and Karoly, D.J. (1981). The steady linear response of a spherical atmosphere to thermal and orographic forcing. J. Atmos. Sci., 38, 1179-1196.

Oort, A.H. and Yienger, J.J. (1996). Observed interannual variability in the Hadley circulation and its connection to ENSO, J. Climate, 9, 2751-2767.

Phipps, S.J. (2010). The CSIRO Mk3L climate system model v1.2, Technical Report No. 4, Antarctic Climate \& Ecosystems CRC, Hobart, Tasmania, Australia, 121 pp., ISBN 978-1-921197-04-8.

Rayner, N.A., Parker, D.E., Horton, E.B., Folland, C.K., Alexander, L.V., Rowell, D.P., Kent, E.C., Kaplan, A. (2003). Global analyses of sea surface temperature, sea ice, and night marine air temperature since the late nineteenth century, J. Geophys. Res., 108, 1-37.

Sardeshmukh, P.D. and Hoskins, B.J. (1988). The generation of global rotational flow by steady idealized tropical divergence, J. Atmos. Sci., 45, 1228-1251.

Tyrrell, G.C. and Karoly, D.J. (1996). Links between tropical convection and variations of the extratropical circulation during TOGA COARE, J. Atmos. Sci., 53(18), 2735-2748.

Zidikheri, M.J. and Frederiksen, J.S. (2013). Methods for estimating climate anomaly forcing functions. $J$. Atmos. Sci., 70, 2655-2679. DOI: http://dx.doi.org/10.1175/JAS-D-12-0304.1 